\title{
Intraocular lens opacification
}

\author{
Opacificação de lente intraocular
}

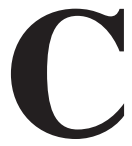

ataract surgery is one of the most commonly-performed surgeries in the world, providing benefits to patients $^{1}$ and society as a whole ${ }^{2}$. Despite technological advances in intraocular lenses (IOLs) to correct spherical aberrations ${ }^{3}$, presbyopia and astigmatism ${ }^{4}$, there are still cases where IOLs need to be explanted due to opacification of their materials ${ }^{5}$.

Since the introduction of intraocular lenses by Ridley in 1949, the manufacturing process of biomaterials has improved continuously. Since 1999 the literature began to report cases of opacification and calcification of implanted IOLs, a problem that used to be considered rare $^{6}$.

Although it is not a common complication of surgery, IOL opacification is highly relevant because it is a major cause of explantation due to symptoms such as glare and low visual acuity?

Over the years many articles have been published reporting cases of early or late opacification, with varying presentations and in IOLs of different materials. Neuhann thus proposed a classification based on the three main types of calcification: primary calcification, which is inherent to the IOL itself and is related to its manufacture and/or storage; secondary calcification, which is due to environmental conditions and factors related to the patient; and false-positive or pseudo-calcification, where other diseases are misdiagnosed as calcification ${ }^{6}$.

Based on many literature reports, it has been noted that opacification can occur in different ways depending on the time period and the IOL materials. During surgery, opacification is usually caused by precipitation of crystalline deposits on the IOL's surface, which can be related to the viscoelastic substance or the balanced saline solution used in the procedure. In the immediate postoperative period there are reports of silicone IOL opacification due to hydration and also due to the interaction of hydrogel material with dyes or the viscoelastic used during surgery. In the late postoperative period, most reports are related to silicone and hydrophilic acrylic IOLs ${ }^{8,9}$.

Laboratory tests show that the opacification of explanted hydrophilic acrylic IOLs is mostly caused by precipitation of calcium and phosphate on and/or within the $\mathrm{IOL}^{10}$. The aetiology of such calcification has not yet been fully understood and may be related to the manufacturing process and even to diseases the patient has. However, other processes may be involved in IOLs made of different materials, such as excessive inflow of water in hydrophobic materials, direct discoloration caused by dyes or medications, and even slow and progressive degradation of the biomaterial ${ }^{8}$.

Over the years, the IOLs most commonly explanted due to opacification were: Hydroview (Bausch \& Lomb), MemoryLens (Ciba Vision), SC60B-OUV (Medical Developmental Research), and Aqua-Sense (Ophthalmic Innovations International) ${ }^{11}$. Despite histochemical and microscopic studies conducted in specialised laboratories, the aetiology of IOL opacification and/or calcification is still unclear, and the subject continues to be studied by many researchers around the world.

One reason for concern is the failure to recognise IOL opacification, which can lead an ophthalmologist to perform inappropriate therapeutic procedures such as posterior capsulotomy with Nd:YAG laser. This would make IOL explantation and implantation a new IOL in the capsular bag more difficult, in addition to subjecting the patient to an unnecessary procedure which is not exempt from complications ${ }^{12}$. 
In order to achieve the goal of providing excellent results to physicians and patients, manufacturers and researchers continue to work on improving the technology used to manufacture and design IOLs, so that cases of IOL opacification will one day become a thing of the past.

\section{Priscilla de Almeida Jorge \\ Ph.D. student, São Paulo University (USP) Member of the editorial board of the Brazilian Journal of Ophthalmology}

\section{ReferenCeS}

1. Temporini ER, Kara N Jr, Jose NK, Holzchuh N. Popular beliefs regarding the treatment of senile cataract. Rev Saude Publica. 2002;36(3):343-9.

2. Kara-Jr N, Sirtoli MG, Santhiago MR, Parede TR, Espíndola RF, Carvalho Rde S. Phacoemulsification versus extracapsular extraction: governmental costs. Clinics (Sao Paulo). 2010;65(4):357-61.

3. Santhiago MR, Netto MV, Barreto J Jr, Gomes BA, Mukai A, Guermandi AP, Kara-Junior N. Wavefront analysis, contrast sensitivity, and depth of focus after cataract surgery with aspherical intraocular lens implantation. Am J Ophthalmol. 2010;149(3):383-9.e1-2.

4. Santhiago MR, Netto MV, Barreto J Jr, Gomes Bde A, Schaefer A, Kara-Junior N. A contralateral eye study comparing apodized diffractive and full diffractive lenses: wavefront analysis and distance and near uncorrected visual acuity. Clinics (Sao Paulo). 2009;64(10):953-60.

5. Ventura BV, Ventura M, Lira W, Ventura CV, Santhiago MR, Werner L. Microscopic analysis of opacification in Ioflex ${ }^{\circledR}$ hydrophilic acrylic intraocular lenses / Análise microscópica da opacificação de lentes intraoculares acrílicas hidrofílicas Ioflex®. Rev Bras Oftalmol. 2012; 71(3):14954 .

6. Neuhann IM, Kleinmann G, Apple DJ. A new classification of calcification of intraocular lenses. Ophthalmology. 2008;115(1):73-9.

7. Mamalis N, Brubaker J, Davis D, Espandar L, Werner L. Complications of foldable intraocular lenses requiring explantation or secondary intervention - 2007 survey update. J Cataract Refract Surg. 2008;34(9):1584-91.

8. Werner L. Causes of intraocular lens opacification or discoloration. J Cataract Refract Surg. 2007;33(4):713-26. Review.

9. Jorge P de A, Jorge D, Ventura CV,Ventura BV, Lira W, Ventura MC, Werner L, Kara N Jr. Late opacification in hydrophilic acrylic intraocular lenses: analysis of 87 eyes in a random sample of 102 patients. J Cataract Refract Surg. 2013;39(3):403-7.

10. Werner L,Apple DJ, Escobar-Gomez M, Ohrström A, Crayford BB, Bianchi R, Pandey SK. Postoperative deposition of calcium on the surfaces of a hydrogel intraocular lens. Ophthalmology. 2000;107(12):2179-85.

11. Werner L. Calcification of hydrophilic acrylic intraocular lenses. Am J Ophthalmol. 2008;146(3):341-3.

12. Haymore J,Zaidman G, Werner L, Mamalis N, Hamilton S, Cook J, Gillette T. Misdiagnosis of hydrophilic acrylic intraocular lens optic opacification: report of 8 cases with the MemoryLens. Ophthalmology. 2007;114(9):1689-95. 